\title{
Co-pyrolysis Behavior of Low-grade Coal and Binder Using High Temperature Solvent Fractionation
}

\author{
Ryuichi ASHIDA, ${ }^{1 * *}$ Sho NAGAYA, ${ }^{11}$ Kouichi MIURA, ${ }^{1)}$ Yukihiro KUBOTA, ${ }^{2)}$ Yuko NISHIBATA ${ }^{3)}$ and \\ Atsushi KOTANI ${ }^{3 !}$
}

1) Department of Chemical Engineering, Kyoto University, Kyoto-daigaku Katsura, Nishikyo-ku, Kyoto, $615-8510$ Japan. 2) Yawata Works, Nippon Steel \& Sumitomo Metal Corporation, 1-1 Tobihata-cho, Tobata-ku, Kitakyushu City, Fukuoka, 8048501 Japan. $\quad 3)$ Research and Development Center, Kansai Coke \& Chemicals Co., Ltd., 1-1 Ohama-cho, Amagasaki-shi, Hyogo, 660-0095 Japan.

(Received on March 31, 2014; accepted on September 15, 2014)

\begin{abstract}
The authors have proposed a high temperature solvent fractionation method that can separate coals into several fractions having different molecular weight without destroying coal structure. In this study the method was applied to characterization of low-grade coals and binder during their co-pyrolysis to clarify chemical interaction between them. When a sub-bituminous coal or a slightly-caking coal was copyrolyzed with asphalt pitch (ASP), it was found that smaller-molecular weight compounds less than 800 in molecular weight which were abundant in ASP could be added by appearance as can be expected from the calculation assuming no interaction between the coals and ASP. The added smaller-molecular weight compounds contributed to the reduction of viscosity of the pyrolyzing coal. The possibility was also suggested that part of smaller-molecular weight compounds in ASP were converted to heavier compounds whereas some smaller-molecular weight compounds were formed from coals to compensate the loss of such compounds derived from ASP. It was also shown that oxygen existent in the heaviest fraction of the low-grade coals was removed to form $\mathrm{H}_{2} \mathrm{O}$ and $\mathrm{CO}_{2}$ by chemical interaction with ASP. This interaction was found to contribute to the reduction of shrinkage of low-grade coals during carbonization.
\end{abstract}

KEY WORDS: coke; binder; co-pyrolysis; high temperature solvent fractionation.

\section{Introduction}

Steel industries need to increase the use of low-grade coals in coke making due to the recent rapid increase in coking coal price. If the conventional coke ovens continue to be used under such circumstances, it is necessary to increase the use of costly binders such as asphalt pitch, which has been believed to be effective in enhancing the coke strength when pyrolyzed and carbonized with coals. ${ }^{1)}$ To minimize the use of the binders, it is necessary to use them in more effective ways based on the mechanism on how the binders contribute to the enhancement of coke strength. However, such mechanism is still unclear, and it is desired to clarify whether the binders act as just glue or there are also chemical interactions to improve the coal properties. ${ }^{2)}$ Physical effect by adding binder has recently been investigated by some researchers. ${ }^{3)}$ In this study chemical interactions between coals and binder were examined by analyzing the chemical structure of coals and binder during their co-pyrolysis in detail.

The authors have proposed a high temperature solvent fractionation method that can separate coals into several fractions having different molecular weight without destroy-

* Corresponding author: E-mail: ashida@cheme.kyoto-u.ac.jp

DOI: http://dx.doi.org/10.2355/isijinternational.54.2432 ing coal structure. ${ }^{4)}$ The method was effective not only in recovering valuable component from coal but also in characterizing coal structure. ${ }^{4-7)}$ In this study the method was applied to characterization of low-grade coals and binder during their co-pyrolysis to clarify chemical interaction between them.

\section{Experimental}

\subsection{Sample Preparation}

A sub-bituminous coal, Adaro coal (AD), a slightly-caking coal, White Haven coal (WH), and a strongly-caking coal, Goonyella coal (GNY) were used in this study. Asphalt pitch (ASP) was used as a binder. The properties of the coals and ASP are given in Table 1.

Each coal was pulverized to less than $1 \mathrm{~mm}$ in diameter prior to pyrolysis with or without ASP. AD mixed with 10 wt $\%$ ASP (AD90 ASP10), WH mixed with $10 \mathrm{wt} \%$ ASP (WH90 ASP10), and WH mixed with $30 \mathrm{wt} \%$ ASP (WH70 ASP30) as well as AD, WH, GNY, ASP were heated up to $450^{\circ} \mathrm{C}$ at $3 \mathrm{~K} / \mathrm{min}$ under inert gas atmosphere. The samples immediately cooled down to room temperature after the heat-treatment were served to high temperature solvent fractionation experiment. 
Table 1. Properties of the coals and ASP used.

\begin{tabular}{|c|c|c|c|c|c|c|c|c|c|}
\hline \multirow{2}{*}{ Coal } & \multirow{2}{*}{ Abbreviation } & \multicolumn{4}{|c|}{ Ultimate analysis [wt $\%$, d.a.f.] } & \multirow{2}{*}{$\frac{\text { Atomic Ratio [-] }}{\mathrm{H} / \mathrm{C}}$} & \multicolumn{3}{|c|}{ Proximate analysis $[\mathrm{wt} \%$, d.b.] } \\
\hline & & $\mathrm{C}$ & $\mathrm{H}$ & $\mathrm{N}$ & $\mathrm{O}+\mathrm{S}$ (diff.) & & VM & $\mathrm{FC}$ & Ash \\
\hline Adaro & $\mathrm{AD}$ & 72.9 & 5.1 & 1.0 & 21.0 & 0.84 & 51.7 & 46.5 & 1.8 \\
\hline White Haven & WH & 81.7 & 5.1 & 1.5 & 11.7 & 0.75 & 34.0 & 57.6 & 8.4 \\
\hline Goonyella & GNY & 87.7 & 4.7 & 1.4 & 6.2 & 0.64 & 22.0 & 66.4 & 11.6 \\
\hline Asphalt Pitch & ASP & 86.9 & 5.8 & 1.2 & 6.1 & 0.80 & 39.9 & 59.7 & 0.4 \\
\hline
\end{tabular}

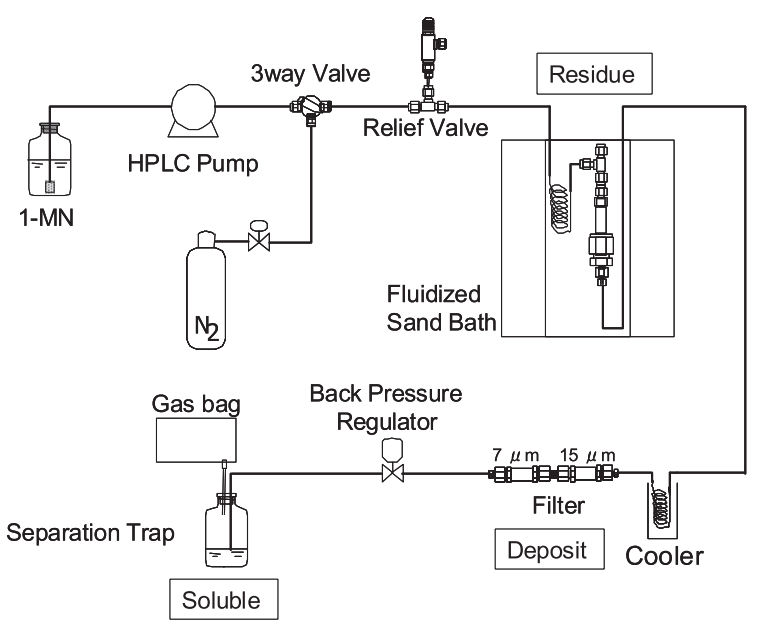

Fig. 1. Schematic diagram of the apparatus used for the high temperature solvent fractionation.

\subsection{Procedure of High Temperature Solvent Fraction- ation}

A schematic diagram of the apparatus used for the high temperature solvent fractionation was shown in Fig. 1. A non-polar solvent, 1-methylnaphthalene was used as the solvent. The procedure of the proposed extraction method has been described in detail in the previous papers. ${ }^{8,9)}$ The fractionation experiment started from the extraction at $250^{\circ} \mathrm{C}$. This extraction separated the sample into the residue, the solid extract that precipitated from the extract at room temperature (deposit), and the extract soluble in solvent even at room temperature (soluble). The deposit obtained by this extraction is a fraction which precipitated as solid at $25^{\circ} \mathrm{C}$ from the extract obtained at $250^{\circ} \mathrm{C}$. This means that the deposit is soluble at $250^{\circ} \mathrm{C}$ but becomes insoluble in 1methylnaphthalene at between $25^{\circ} \mathrm{C}$ and $250^{\circ} \mathrm{C}$. From this viewpoint, the deposit obtained by the $250^{\circ} \mathrm{C}$ extraction is represented as "Frac. $+25-250$ ". Then the residue and the soluble obtained by the $250^{\circ} \mathrm{C}$ extraction are, respectively, referred to as "Frac. +250 " and "Frac. -25 " here. Next, the Frac. +250 was subjected to the extraction at $350^{\circ} \mathrm{C}$, which fractionated the Frac. +250 into Frac. $+250-350$ and Frac. +350 . All the fractions except Frac. -25 were obtained as solid. The solvent dissolving the Frac. -25 was evaporated at around $140^{\circ} \mathrm{C}$ under reduced pressure to recover the Frac. -25 as a solid.

\subsection{Analyses of the Fractions Obtained by High Tem- perature Solvent Fractionation}

The fractions obtained were characterized through various analyses. The laser desorption/ionization time-of-flight mass spectrometry (MALDI-TOFMS; Shimadzu/Kratos KOMPACT-MALDI-II) was used to estimate the molecular

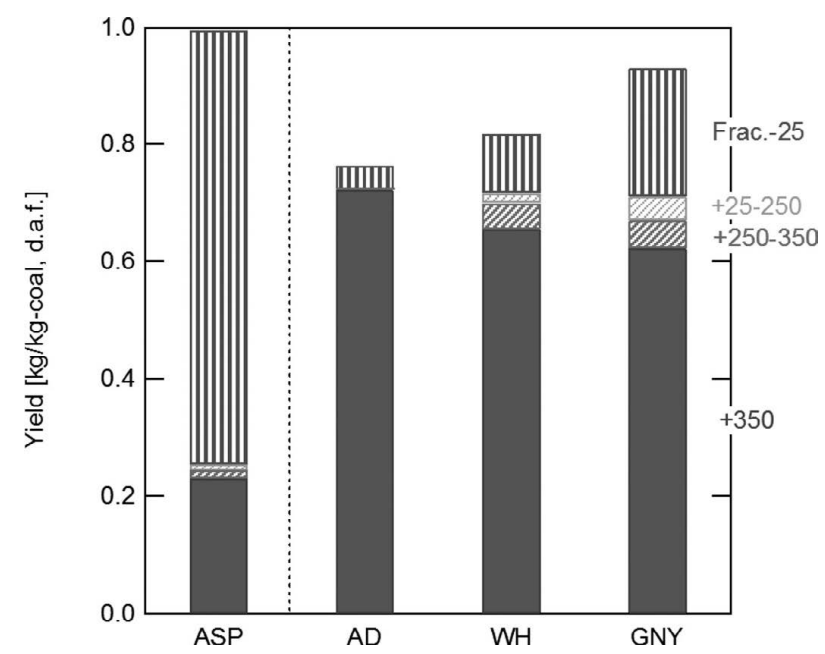

Fig. 2. Yield of each fraction for the coals and ASP heated up to $450^{\circ} \mathrm{C}$.

weight distributions of the fractions obtained. The MALDI spectrometer is equipped with an $\mathrm{N}_{2} \mathrm{UV}$ laser of $337 \mathrm{~nm}$ in wavelength and its acceleration voltage could be chosen as either $5 \mathrm{kV}$ (low mode) or $20 \mathrm{kV}$ (high mode). Laser power was carefully selected from the power range where the molecular weight distribution of the sample did not change with the laser power in order to avoid decomposition of the sample. Ultimate analyses of the fractions were performed using a CHN analyzer (Yanaco, MT-6). Sulfur contents of the fractions were determined by a combustion-infrared absorptiometric method. Determination of type and distribution of hydrogen in Frac. -25 was performed by ${ }^{1} \mathrm{H}$ NMR analyses (JEOL, ECX-400). Weight decreasing curves of the fractions were measured using a thermobalance type reactor (Shimadzu; TGA50) during the heating up at a rate of $10 \mathrm{~K} /$ min up to $900^{\circ} \mathrm{C}$ in a nitrogen stream. Under the same heating conditions the softening/melting and shrinking behaviors of the fractions were examined using a thermomechanical analyzer (Shimadzu; TMA50) in which the displacement depth of a rod into a solid sample bed was continuously monitored. Solid sample was placed in a pan (5.2 $\mathrm{mm}$ I.D. and $6.0 \mathrm{~mm}$ high) at the height of $1 \mathrm{~mm}$. The rod of $4.3 \mathrm{~mm}$ in diameter was loaded with a constant load of $0.098 \mathrm{~N}$ for the measurement.

\section{Results and Discussion}

Figure 2 shows the yield of each fraction for the coals and ASP heated up to $450^{\circ} \mathrm{C}$. The strongly-caking coal, GNY was the richest in the extracted fractions, Frac. -25 , Frac. $+25-250$, and Frac. $+250-350$ among the coals tested while the subbituminous coal, $\mathrm{AD}$ was the poorest in these fractions. 
Frac. -25 accounted for as large as $75 \%$ of ASP. These results suggest that abundance of Frac. -25 , Frac. $+25-250$, and Frac. $+250-350$ reflects the better fusibility.

Figure 3 shows the yield of each fraction for the coals copyrolyzed with ASP up to $450^{\circ} \mathrm{C}$. The figure also shows the yield calculated from the data shown in Fig. 2 assuming no interaction between the coals and ASP. The yield of Frac.-25 for co-pyrolysis was a little smaller than the calculated Frac.-25 yield for WH70 ASP30, whereas the yield of Frac. +350 was close to the calculated yield. Compositions for the co-pyrolyzed samples were similar to the calculated compositions for AD90 ASP10 and WH90 ASP10. In other words, the composition of low-grade coals such as WH or AD can be made similar to that of the high-grade GNY coal by adding ASP as can be expected from the amount of ASP added.

Figure 4 shows molecular weight distributions of Frac. -25 . The distributions were not dependent on the kind of the raw materials and were similar whether co-pyrolyzed or not. Any Frac. -25 consisted of compounds less than 800 in

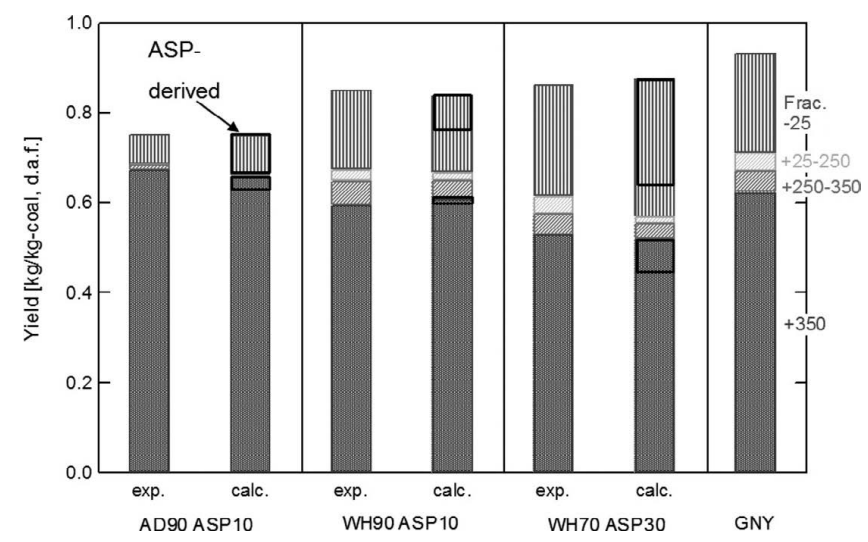

Fig. 3. Yield of each fraction for the coals co-pyrolyzesd with ASP up to $450^{\circ} \mathrm{C}$ and the yield calculated assuming no interaction between the coals and ASP.

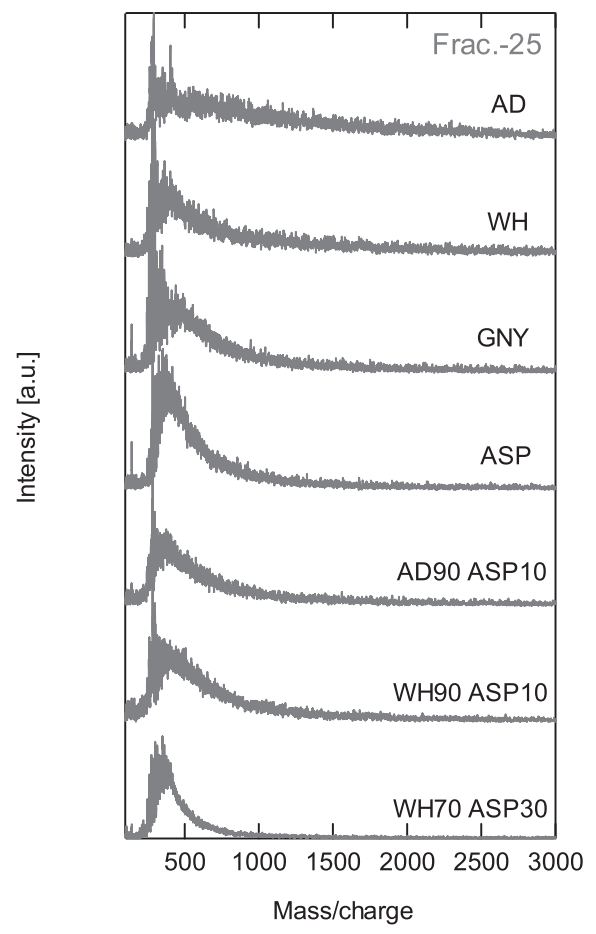

Fig. 4. Molecular weight distributions of Frac. -25 . molecular weight and a peak of the distribution appeared at around 300 in molecular weight. The molecular weight distributions of the other fractions were not different among the original samples as well. Reflecting these similarities of molecular weight, softening and melting behaviors of each fraction did not largely depend on their origins as seen in TMA curves typically shown for Frac. -25 in Fig. 5. All the Frac. -25 melted at around $100^{\circ} \mathrm{C}$ while all the Frac. +350

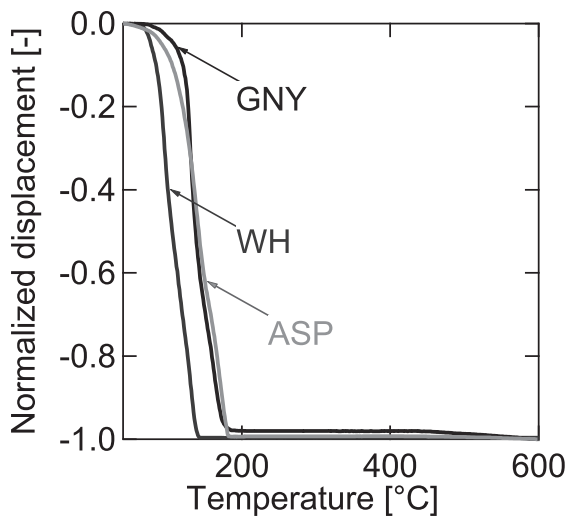

Fig. 5. Thermomechanical analysis (TMA) curves for Frac. -25 .

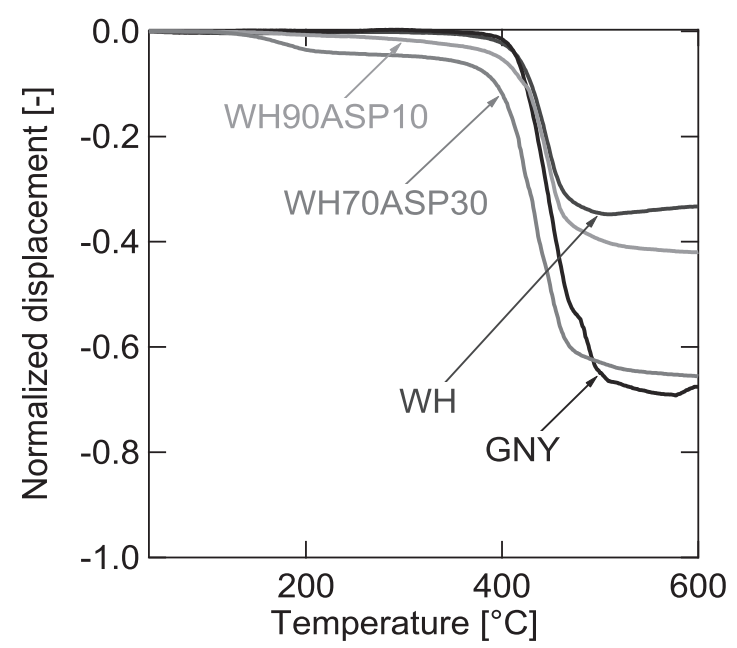

Fig. 6. TMA curves of WH, WH with ASP, and GNY.

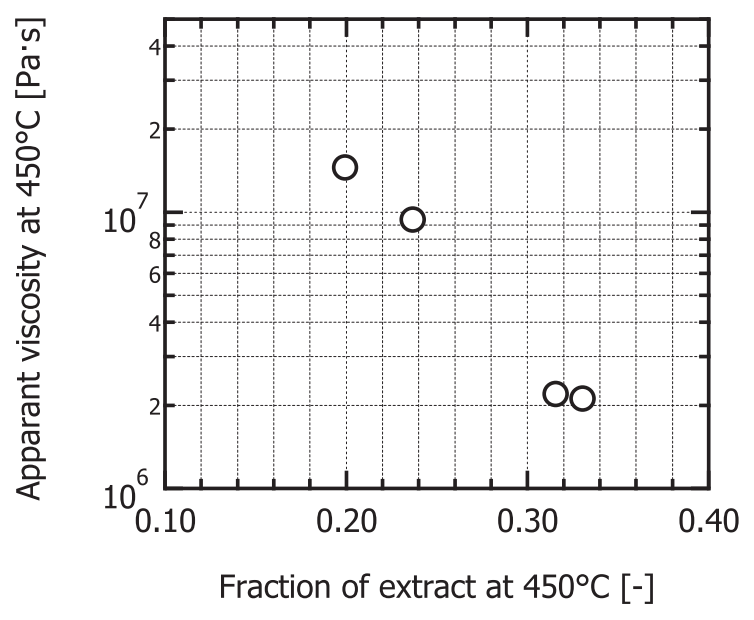

Fig. 7. Relationship of apparent viscosity at $450^{\circ} \mathrm{C}$ estimated from TMA curves shown in Fig. 6 and relative abundance of the extracted fractions at $450^{\circ} \mathrm{C}$ (Frac. -25 , Frac. $+25-250$, and Frac. $+250-350$ ) 
didn't melt at all.

Since molecular weight distributions and softening/melting behaviors of each fraction were not significantly different among the samples, softening and melting behaviors of the coals co-pyrolyzesd with ASP are expected to depend on the relative abundance of each fraction. Figure 6 compares TMA curves of WH, WH with ASP, and GNY. The softening and melting behaviors of WH became closer to that of GNY with the increase of ASP added as expected from the fact that smaller molecular weight compounds such as Frac. -25 was increased by addition of ASP, which was shown in Fig. 3. Figure 7 shows a plot of apparent viscosity at $450^{\circ} \mathrm{C}$ estimated from TMA curves shown in Fig. 6 by assuming that the samples behave as a Newtonian fluid ${ }^{6}$ against relative abundance of the extracted fractions (Frac.-25, Frac. $+25-250$, and Frac. $+250-350$ ). The estimated apparent viscosity decreased with the increase of the extracted fractions, indicating that the viscosity of the coals or coals with ASP was dominated by relative abundance of smaller molecular weight compounds which could be controlled by the amount of ASP added.

It was thus shown that the molecular weight distribution and softening/melting behavior of each fraction were not dependent on the kind of the raw materials and were similar whether co-pyrolyzed or not, and that the softening/melting behaviors of the coals co-pyrolyzed with ASP were correlated with relative abundance of smaller molecular weight compounds, whose increase when ASP was added corresponded to the amount of such compounds in ASP by appearance. Analysis of elemental composition and hydro- gen type distribution of the fraction, however, show some chemical interaction in co-pyrolysis between coal and ASP. Table 2 shows elemental compositions of the fractions obtained from coals, ASP, and coals with ASP heated up to $450^{\circ} \mathrm{C}$. Elemental compositions calculated by assuming no interaction between coals and ASP are also shown in Table 2. While hydrogen contents of Frac. -25 decreased when copyrolyzed, oxygen contents of Frac. +350 significantly decreased. These differences were more significant for the lower-grade coal, AD. These interactions made the elemental composition of each fraction closer to that of GNY. Figure 8

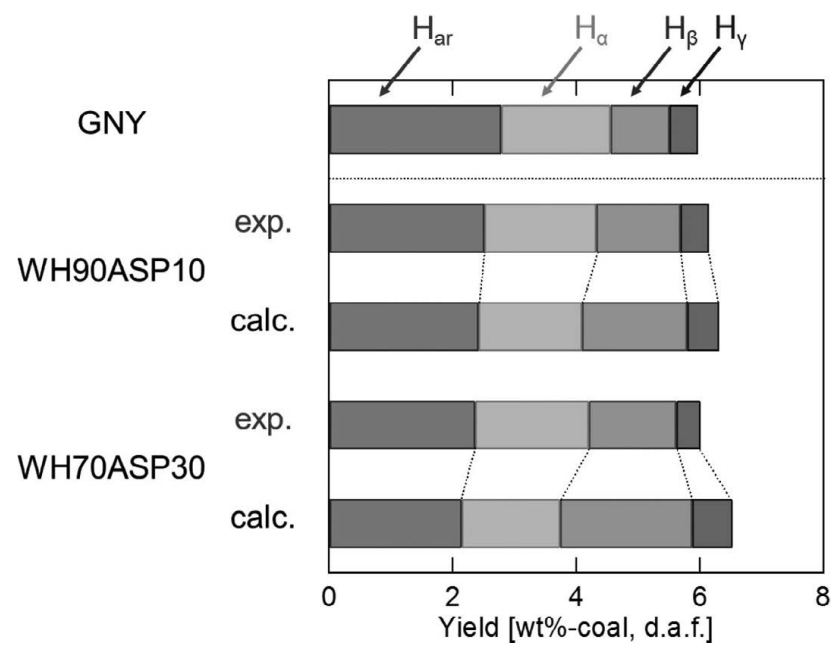

Fig. 8. Comparison of hydrogen type distributions of Frac.-25 for co-pyrolysis (exp.) with the calculated value (calc.).

Table 2. Elemental compositions of the fractions obtained from coals, ASP, and coals with ASP heated up to $450^{\circ} \mathrm{C}$ and those calculated by assuming no interaction between coals and ASP.

\begin{tabular}{|c|c|c|c|c|c|c|c|c|}
\hline & & & \multicolumn{5}{|c|}{ Ultimate analysis [wt $\%$, d.a.f.] } & \multirow{2}{*}{$\frac{\text { Atomic Ratio [-] }}{\mathrm{H} / \mathrm{C}}$} \\
\hline & & & $\mathrm{C}$ & $\mathrm{H}$ & $\mathrm{N}$ & $\mathrm{S}$ & $\mathrm{O}$ (diff.) & \\
\hline \multirow{10}{*}{ Frac. -25} & $\mathrm{AD}$ & & 82.3 & 5.7 & 0.9 & 0.3 & 10.7 & 0.83 \\
\hline & WH & & 85.2 & 6.0 & 1.4 & 0.6 & 6.8 & 0.85 \\
\hline & GNY & & 86.6 & 6.0 & 1.2 & n.m. & $6.2 *$ & 0.83 \\
\hline & ASP & & 84.8 & 6.7 & 1.0 & 5.1 & 2.4 & 0.95 \\
\hline & \multirow{2}{*}{ AD90 ASP10 } & exp. & 84.6 & 6.0 & 0.9 & 3.1 & 5.3 & 0.86 \\
\hline & & cal. & 84.8 & 6.7 & 1.0 & 5.1 & 2.4 & 0.94 \\
\hline & \multirow{2}{*}{ WH90 ASP10 } & exp. & 85.4 & 6.1 & 1.1 & 2.0 & 5.4 & 0.86 \\
\hline & & cal. & 85.0 & 6.3 & 1.2 & 2.7 & 4.8 & 0.89 \\
\hline & \multirow{2}{*}{ WH70 ASP30 } & exp. & 86.3 & 6.0 & 1.1 & n.m. & $6.6^{*}$ & 0.83 \\
\hline & & cal. & 84.9 & 6.5 & 1.1 & 4.1 & 3.4 & 0.92 \\
\hline \multirow{10}{*}{ Frac. +350} & $\mathrm{AD}$ & & 77.6 & 3.8 & 1.2 & 0.3 & 17.1 & 0.58 \\
\hline & WH & & 82.5 & 4.0 & 1.0 & 0.4 & 12.1 & 0.58 \\
\hline & GNY & & 86.9 & 4.1 & 1.5 & n.m. & $7.5^{*}$ & 0.57 \\
\hline & ASP & & 85.1 & 4.2 & 1.2 & 8.5 & 1.0 & 0.59 \\
\hline & \multirow{2}{*}{ AD90 ASP10 } & exp. & 82.6 & 4.1 & 1.3 & 0.8 & 11.2 & 0.60 \\
\hline & & cal. & 77.9 & 3.8 & 1.2 & 0.7 & 16.4 & 0.58 \\
\hline & \multirow{2}{*}{ WH90 ASP10 } & exp. & 85.0 & 4.2 & 1.4 & 0.9 & 8.5 & 0.59 \\
\hline & & cal. & 83.8 & 4.2 & 1.6 & 0.8 & 9.6 & 0.60 \\
\hline & \multirow{2}{*}{ WH70 ASP30 } & exp. & 86.7 & 4.3 & 1.5 & n.m. & $7.5^{*}$ & 0.60 \\
\hline & & cal. & 83.9 & 4.2 & 1.6 & 1.6 & 8.7 & 0.60 \\
\hline
\end{tabular}

n.m.: not measured, *O+S (diff.) 
compares hydrogen type distributions of Frac. -25 for copyrolysis (exp.) with the calculated value. $\mathrm{H}_{\mathrm{ar}}, \mathrm{H}_{\alpha}, \mathrm{H}_{\gamma}$, and $\mathrm{H}_{\beta}$, in Fig. 8 respectively represent aromatic hydrogen, hydrogen on $\alpha$ position carbon, peripheral methyl hydrogen, and hydrogen on $\beta$ position carbon and the other carbons. The amount of aliphatic hydrogens, $\mathrm{H}_{\alpha}, \mathrm{H}_{\beta}$, and $\mathrm{H}_{\gamma}$, for $\mathrm{WH}$ coal co-pyrolyzed with ASP was smaller than the calculated one whereas the amount of aromatic hydrogens, $\mathrm{H}_{\mathrm{ar}}$ for $\mathrm{WH}$ coal co-pyrolyzed with ASP was larger than the calculated one. These results imply that chemical reactions took place between coals and ASP which made hydrogen type distributions of Frac. -25 closer to that of GNY. $\mathrm{CO}_{2}$ formed in co-pyrolysis was more than the calculated value as shown in Fig. 9, which seems consistent with the decrease of oxygen of Frac. +350 in co-pyrolysis.

Figure 10 shows sulfur distribution for coals and ASP heated up to $450^{\circ} \mathrm{C}$. The ASP heated up to $450^{\circ} \mathrm{C}$ contained totally as large as 5.8\%-d.a.f. sulfur whereas $\mathrm{WH}$ and $\mathrm{AD}$ heated up to $450^{\circ} \mathrm{C}$ contained less than $0.3 \%$-d.a.f. sulfur. Considering sulfur in ASP as a tracer element, interaction between the coals and ASP in co-pyrolysis was examined. Figure 11 compares sulfur distributions for co-pyrolysis (exp.) with those calculated by assuming no interaction between coals and ASP (calc.). Less sulfur was distributed to Frac. -25 and more sulfur was distributed to Frac. +350 for co-pyrolysis than the calculated value. Since almost all the sulfur in Frac. -25 was originated from ASP, this result indicates that part of Frac.-25 of ASP was converted to

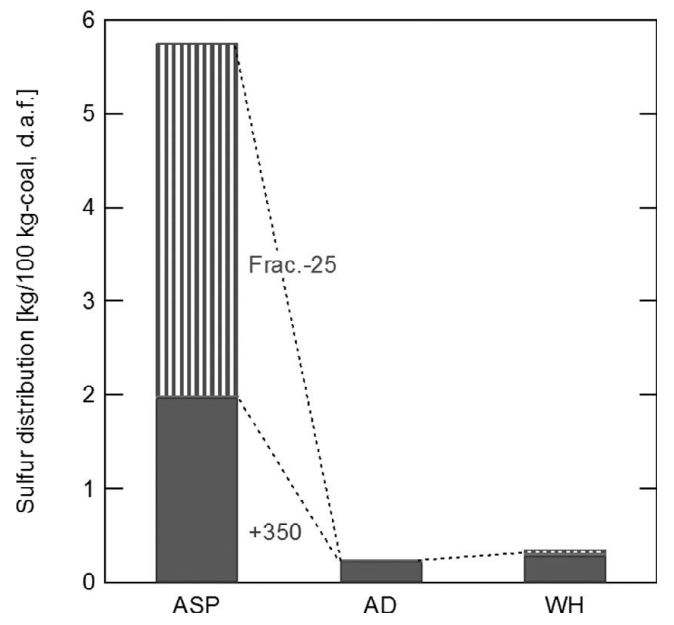

Fig. 10. Sulfur distribution for coals and ASP heated up to $450^{\circ} \mathrm{C}$.

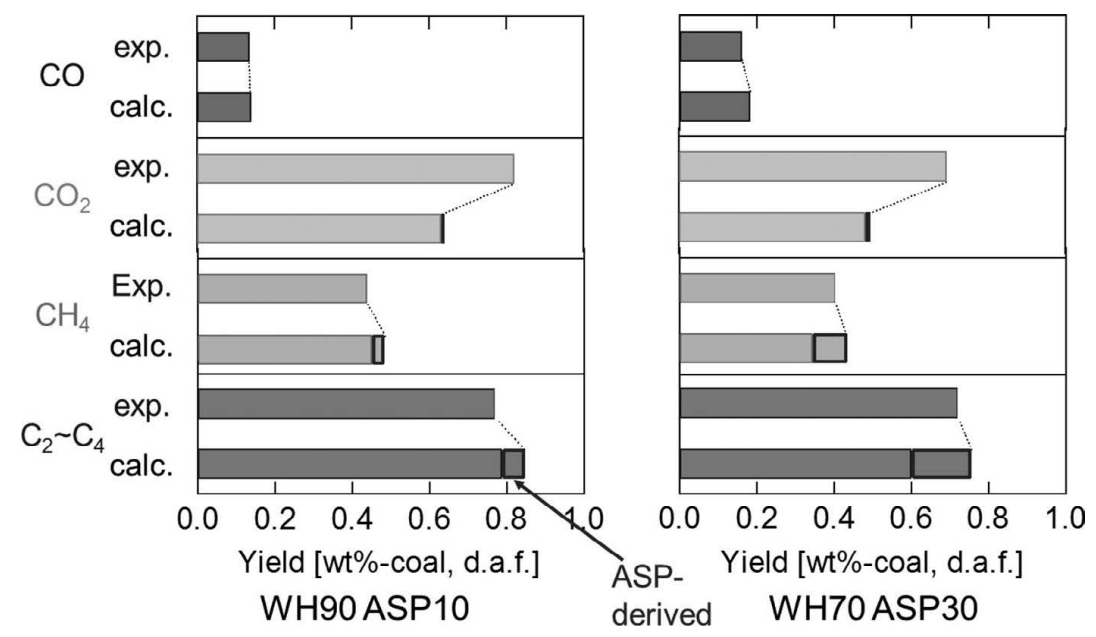

Fig. 9. Comparison of gas yields produced in co-pyrolysis (exp.) with the gas yield calculated assuming no interaction between the coals and ASP (calc.).
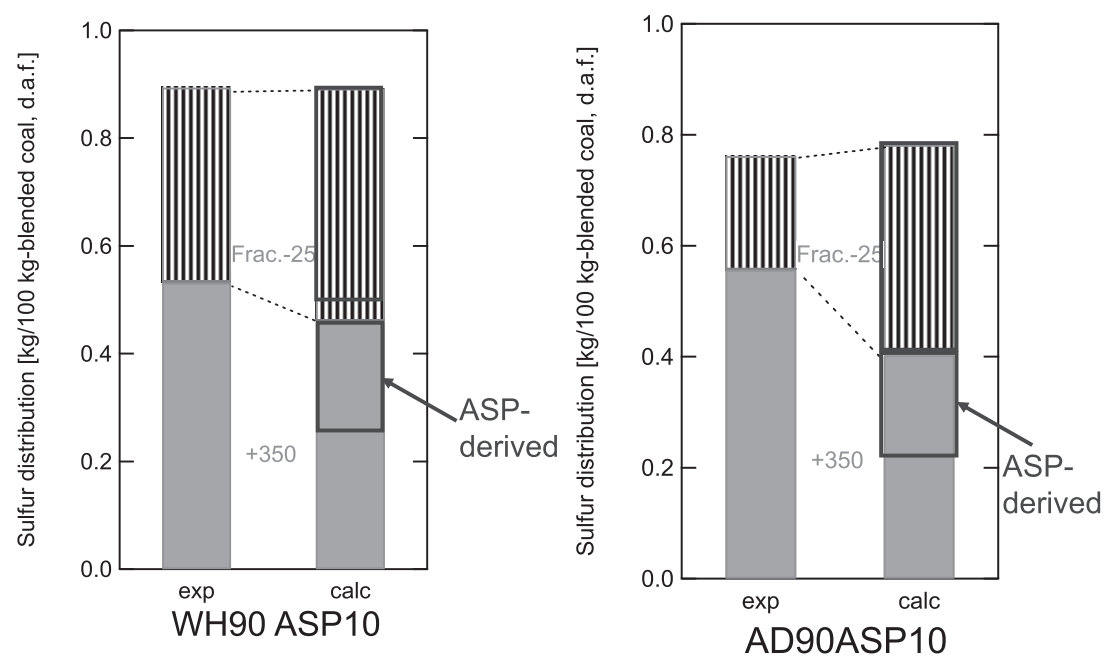

Fig. 11. Sulfur distributions for co-pyrolysis (exp.) with those calculated by assuming no interaction between coals and ASP (calc.). 
Frac. +350 by the chemical reactions between coals and ASP. As the yield of Frac.-25 for co-pyrolysis was almost the same as the calculated value by appearance, coal-derived Frac. -25 should have increased by the reactions with ASP on the other hand. The conversion of some heavier compounds of the coal into smaller molecular compounds, Frac. -25 might be due to hydrogen supply from ASP since part of ASP in turn changed to heavier compounds. Although the significant chemical interactions are suggested, apparent abundance of smaller-molecular weight compounds was not significantly affected by the interaction. Therefore, the chemical interaction did not inhibit the reduction of viscosity by adding ASP.

Figure 12 compares the balance of each element in copyrolysis with the calculated balance. The balances were shown for $100 \mathrm{~mol}$ carbons of the raw coals. The calculated balance for WH shows that Frac. +350 contained $7.7 \mathrm{~mol}$ oxygens for $69 \mathrm{~mol}$ carbons. In co-pyrolysis, on the other

\section{WH9OWH10 C}

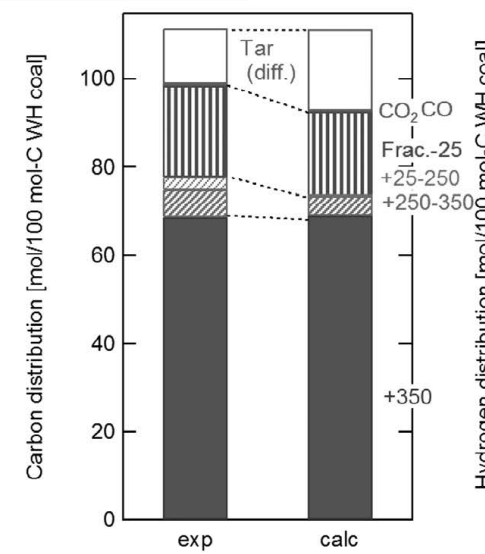

AD90WH10 C

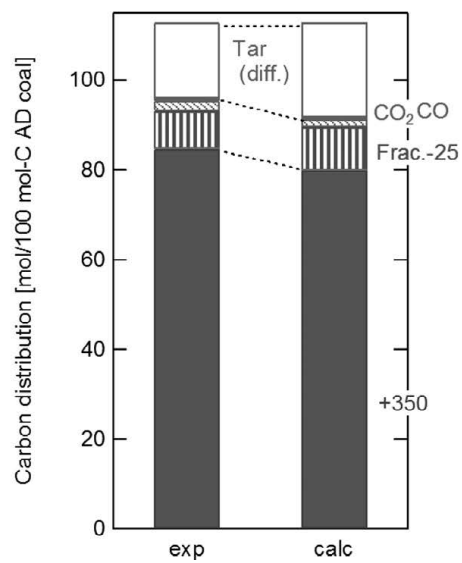

$\mathrm{H}$

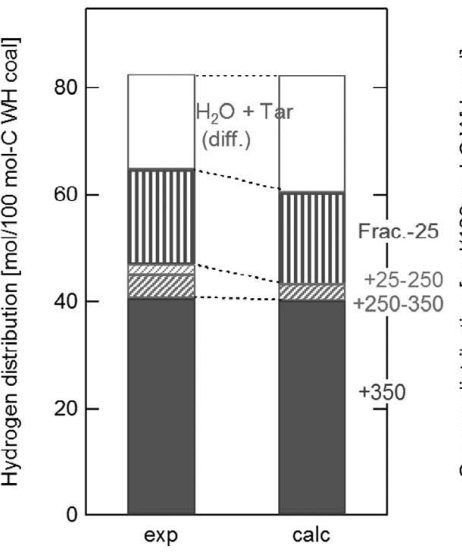

$\mathrm{H}$

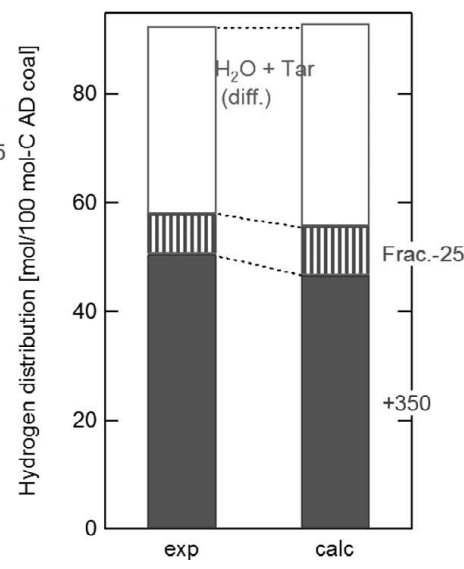

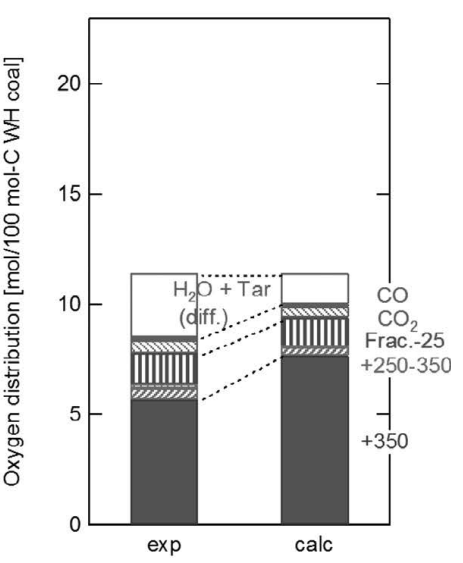

O

Fig. 12. Comparison of the balance of each element in co-pyrolysis (exp.) with the calculated balance (calc.).
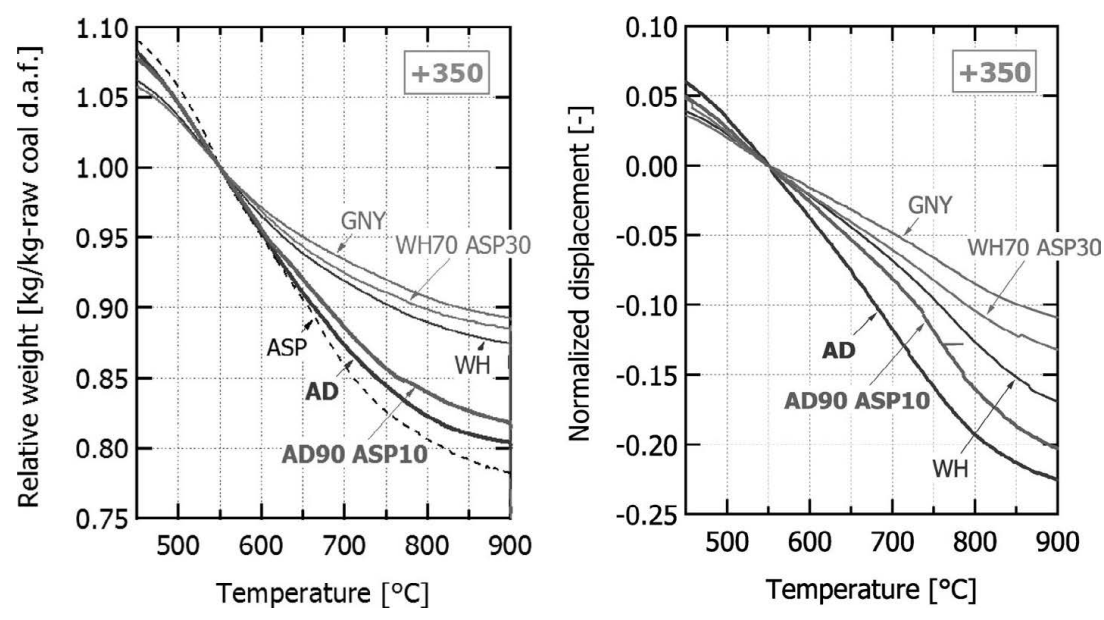

Fig. 13. Thermogravimetric curves (right) and thermomechanical analysis curves (left) for Frac. +350 obtained from coals, ASP, and coals with ASP heated up to $450^{\circ} \mathrm{C}$. 
hand, Frac. +350 contained $5.7 \mathrm{~mol}$ oxygens for $69 \mathrm{~mol}$ carbons. For $\mathrm{AD}$, the calculated balance shows that Frac. +350 contained $13.2 \mathrm{~mol}$ oxygens for $80 \mathrm{~mol}$ carbons while Frac. +350 contained much less $9.2 \mathrm{~mol}$ oxygens for $85 \mathrm{~mol}$ carbons in co-pyrolysis. Since these decreases of oxygen in Frac. +350 in co-pyrolysis cannot fully be explained by the increase of $\mathrm{CO}_{2}$ yield, it was suggested that oxygen in Frac. +350 were mainly removed as $\mathrm{H}_{2} \mathrm{O}$ by interaction between coals and ASP.

It was thus found that oxygen of the main constituent of the coals, Frac. +350 , was removed by the chemical interaction with ASP. To investigate what this interaction would bring about, thermal behaviors of Frac. +350 were examined. Figure 13 shows thermogravimetric curves and thermomechanical analysis curves for Frac. +350 obtained from coals, ASP, and coals with ASP heated up to $450^{\circ} \mathrm{C}$. Weight loss and shrinkage of Frac. +350 were more significant for AD and WH than for GNY. However, weight loss and shrinkage of Frac. +350 for $\mathrm{WH}$ and $\mathrm{AD}$ were decreased when copyrolyzed with ASP. This was presumably due to the reduction of oxygen in Frac. +350 by interaction with ASP up to $450^{\circ} \mathrm{C}$, which resulted in the reduction of $\mathrm{CO}, \mathrm{CO}_{2}$, and $\mathrm{H}_{2} \mathrm{O}$ formation during carbonization at higher than $550^{\circ} \mathrm{C}$. Since Frac. +350 is the main constituent of coals, the reducing effect of shrinkage found for Frac. +350 could lead to the shrinkage reduction of the coal, which should be one of the important roles of the binder.

\section{Conclusions}

Interactions between low-grade coals and a binder, ASP, during their co-pyrolysis were investigated by utilizing the high temperature solvent fractionation method the authors proposed.

When low-grade coals were co-pyrolyzed with ASP, it was found that smaller-molecular weight compounds (Frac.-25) which were abundant in ASP could be added by appearance as can be expected from the calculation assuming no interaction between the coals and ASP. The added smaller-molecular weight compounds contributed to the reduction of viscosity of the pyrolyzing coal. The possibility was also suggested that part of smaller-molecular weight compounds in ASP were converted to heavier compounds whereas some smaller-molecular weight compounds were formed from the coals to compensate the loss of such compounds derived from ASP.

It was clarified that oxygen existent in the heaviest fraction (Frac. +350 ) of the low-grade coals was removed to form $\mathrm{H}_{2} \mathrm{O}$ and $\mathrm{CO}_{2}$ by chemical interaction with ASP. This interaction was found to contribute to the reduction of shrinkage of low-grade coals during carbonization.

\section{Acknowledgements}

This work has been done in the ISIJ research group on "Cokemaking Technologies for Low-Quality and Unused Carbon Resources" (Chief Manager: Prof. Hideyuki Aoki, Tohoku University). The authors are grateful to all the research group members.

\section{REFERENCES}

1) Y. Sunami, K. Nishioka, M. Ogawa and T. Kiritani: J. Fuel Soc. Jpn., 58 (1979), 860

2) T. Arima, S. Aizawa and S. Nomura: Tetsu-to-Hagané, 100 (2014), 110.

3) Y. Hayashi, S. Aizawa, K. Uebo, S. Nomura and T. Arima: Tetsu-toHagané, 100 (2014), 118.

4) R. Ashida, K. Nakagawa, M. Oga, H. Nakagawa and K. Miura: Fuel, 87 (2008), 576

5) R. Ashida, M. Morimoto, Y. Makino, S. Umemoto, H. Nakagawa, K. Miura, K. Saito and K. Kato: Fuel, 88 (2009), 1485.

6) R. Ashida, A. Hagimoto, K. Miura, N. Okuyama, M. Hamaguchi, T. Shishido and N. Komatsu: J. Jpn. Inst. Energy, 91 (2012), 48.

7) R. Ashida, K. Takashima, K. Miura, N. Okuyama, M. Hamaguchi and T. Shishido: Tetsu-to-Hagané, 100 (2014), 127.

8) K. Miura, M. Shimada and K. Mae: Proc. of 15th Pittsburgh Coal Conf., Paper No. 30-1, University of Pittsburgh, Pittsburgh, (1998).

9) M. Miura, K. Mae, H. Shindo, R. Ashida and T. Ihara: J. Chem. Eng. Jpn., 36 (2003), 742. 